\title{
The model of close relationships in Russian youth
}

Salitova M, Zinovieva E, Kazantseva T, Pleshkova A. Saint-Petersburg State University

Developing close relationships which are characterised by demonstration of personal attachment to the partner, a desire to open up emotionally and sexual attraction is a significant need for most young people, and also an important factor in their development. Most often, the choice of a partner and the scrip to build intimate relationships depends on the value representations about the family (Byng-Hall, 1985), and the behavior patterns observed in parental family that can be regarded as an aspect of intergenerational transmission.

In studies analysing intergenerational transmission of working models of intimate relationships, the similarities and discrepancies in representations of parents and children were found (Grigorova, 2016). Currently, we are witnessing generational shifts in the phenomenology of close relationships that lead to conflicting ideas about intimacy among young people. However, the essence of these contradictions is not well understood and described.
The study was aimed to describe the model of intimate relationships in representations of young people based on their image of parental family and their future family.

The study involved 80 respondents from full families; 39 men and 41 women, mean age $=$ $21.8 \pm 1.42$ years old.

Method: a questionnaire for identifying the representations of intimate relationships in one's own future family and in parental family; the questionnaire "Role Expectations and Preferences in Marriage (ROP)" by A.N. Volkova; the method "Evaluation of the sexual profile" by O.F. Potemkina, C. Osgud Semantic Differential technique. Parametric tstudent test, Chi-square Pearson test were used for data processing.
The data analysis had showed a greater willingness of young people, compared to their parents, to openly express their feelings, privately and on public, verbally and nonverbally; to feel more relaxed in demonstrating their naked body ( $p \geq 0.003$ ). Significant differences emerged $(p<0.001)$ in such parameters as "parental-educational sphere" and "social activity" ( $p<0.001)$ and in representations of the sexual sphere in parental family and one's own family. And a similarity was found in the parameters "emotional support" and "identification with a partner".
The obtained data showed that the model of intimate relationships in young people had similarities with the representations of relationships in parental family in terms of the parameters of personal identification with the partner and emotional-psychotherapeutic support from the partner. The differences lie in the importance of common extra-familial interests, as the basis for building and maintaining relationships, and the meaning of the sexual intimacy. For young people, the sexual sphere is more important than, in their opinion, for their parents, who, in order to maintain family relationships, focus on parental functions and on household duties.

The results of the questionnaire "Role Expectations and Preferences in Marriage". The comparison of the respondents' model of future intimate relationships with the representations of parental models of intimate relationships.

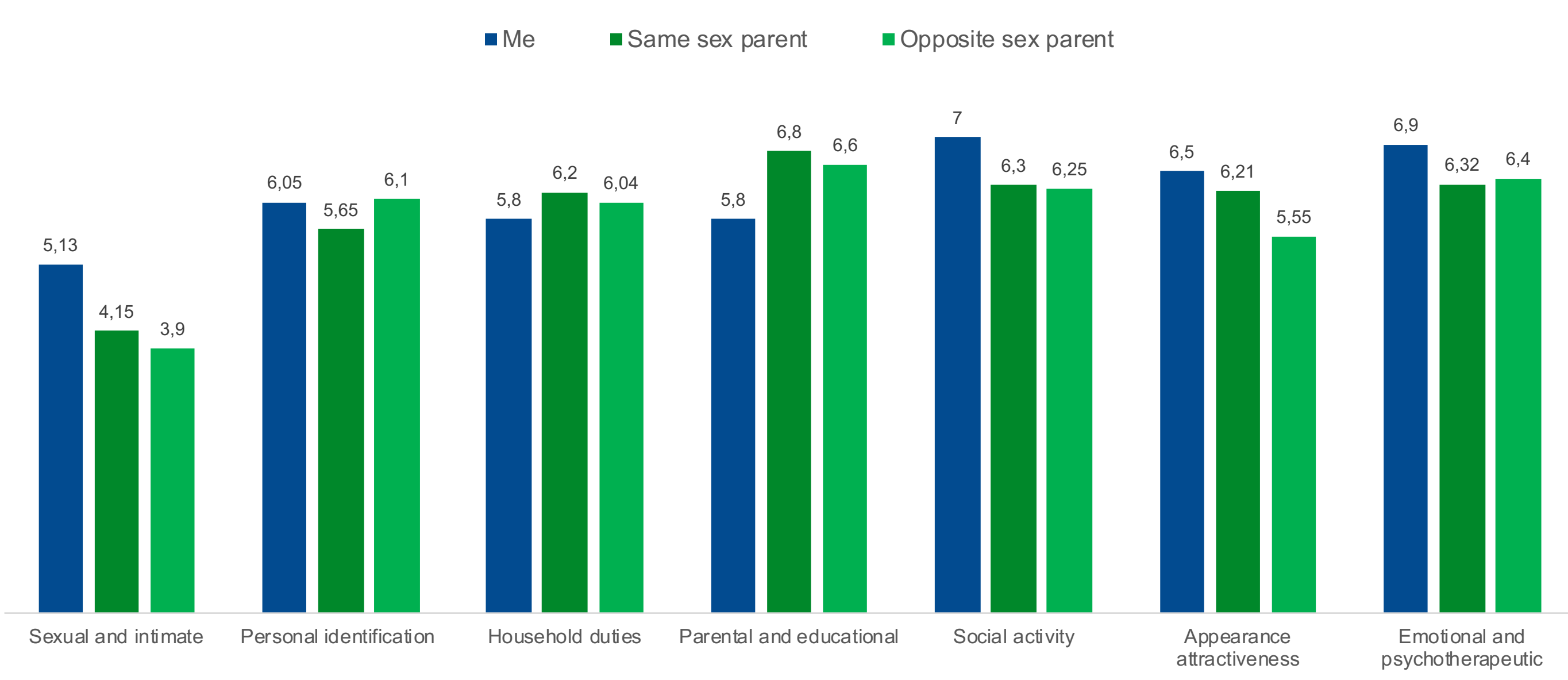

